Ann. Geophysicae 16, 1014-1023 (1998) ㄷ EGS - Springer-Verlag 1998

\title{
Planetary wave activity in the lower ionosphere during CRISTA I campaign in autumn 1994 (October-November)
}

\author{
D. Pancheva ${ }^{1}$, J. Laštovička ${ }^{2}$ \\ ${ }^{1}$ Geophysical Institute, Bulg. Acad. Sci., Acad. G. Bonchev str.” bl.3, BG-1113 Sofia, Bulgaria \\ ${ }^{2}$ Institute of Atmospheric Physics, Acad. Sci. Czech Rep., Bočni II, CR-14131 Prague 4, Czech Republic
}

Received: 3 September 1997 / Revised: 18 February 1998 / Accepted: 24 February 1998

\begin{abstract}
On the basis of MEM spectrum analysis, the main planetary scale fluctuations formed in the lower ionosphere are studied over a period of 3-25 days during the CRISTA campaign (October-November 1994). Three dominant period bands are found: $3-5,6-8$ and 15-23 (mainly 16-18) days. For 7-8 and 16-18 day fluctuations, propagation was eastward with wave numbers $K=3$ and $K=1$, respectively. The magnitude of planetary wave activity in the mid-latitudes of the Northern Hemisphere during the CRISTA campaign seems to be fairly consistent with the expected undisturbed normal/climatological state of the atmosphere at altitudes of $80-100 \mathrm{~km}$.
\end{abstract}

Key words. Ionosphere (ionosphere-atmosphere interactions) - Meteorology and atmospheric dynamics (middle atmosphere dynamics; waves and tides)

\section{Introduction}

Planetary wave activity in the upper middle atmosphere at mid-latitudes has predominantly been studied in winter, partly as a comparison with summer conditions. Little is known about planetary wave activity in late autumn, October to November. The aim of this study is to look at planetary wave activity in October-November 1994 based on radio propagation data from the lower ionosphere $(h=80-100 \mathrm{~km})$ collected during the international CRISTA campaign. It is continuation of our previous study made for the DYANA winter campaign (Pancheva et al., 1994), January-March 1990. Information on planetary wave activity in the upper middle

Correspondence to: J. Laštovička

E-mail: jla@ufa.cas.cz atmosphere, inferred from radio wave absorption, has predominantly been used to study long-term trends in planetary wave activity (e.g. Laštovička et al., 1994c, Laštovička, 1997, and references herein). Response to planetary scale activity in the stratosphere has also been studied (Pancheva et al., 1991) as well as to some other phenomena. It should be mentioned that studies of planetary wave-type oscillations in radio wave absorption were initiated in the late 1960s and early 1970 (e.g. Schwentek, 1974 and references herein). Then after more than a decade of no activity in the field they were revitalized in the late 1980s.

The CRISTA campaign was devoted to investigations of the small-scale structures in atmospheric dynamics, temperature, photochemistry and the energy budget of the middle atmosphere. The international CRISTA campaign was a large international campaign of rocket, balloon and ground-based measurements associated with the CRISTA (CRyogenic Infrared Spectrometers and Telescopes for the Atmosphere) and MAHRSI (Middle Atmosphere High Resolution Spectrometer Instrument) experiments launched by a US space shuttle. CRISTA is a limb sounding infrared experiment to measure small-scale disturbances in trace gas distributions and temperature, predominantly in the middle atmosphere (e.g. Offermann et al., 1994). The period of active CRISTA work was 4-12 November, the supporting campaign was from 27 October to 25 November 1994, and ionospheric campaign from 1 October to 30 November.

The ionospheric measurements made during the campaign serve four purposes:

1. A general description of the state of the lower ionosphere during the campaign and its response to meteorological and solar/geomagnetic forcing (paper under preparation).

2. Utilization of the long-term ionospheric measurements for answering the question whether the campaign was run under representative (climatological) or rather unusual conditions (partial answer can be found in Laštovička et al., 1997). 
3. Description of planetary wave activity in the lower ionosphere.

4. Description of gravity wave activity in the lower ionosphere (over central Europe see Laštovička et al., 1997).

For an earlier campaign DYANA (winter 1990), items (1) and (2) were considered in Laštovička et al. (1994a), item (3) by Pancheva et al. (1994) and item (4) by Hauchecorne et al. (1994).

The subject of this work is an analysis of planetary wave activity in the upper part of the lower ionosphere (about $80-100 \mathrm{~km}$ ) as inferred from ionospheric radio propagation measurements, mainly from the A3 absorption (oblique incidence on the ionosphere), its substitute/proxy $f_{\min }$ parameter determined from ionograms, and from the indirect phase reflection height measurement analysis (IPHA). The IPHA method has been described by Lauter et al. (1984). The A3 method of absorption measurements has been described in its HF version e.g. by Laštoviěka and Maděra (1982) as used for $1539 \mathrm{kHz}$ measurements, and in its LF version by Lauter et al. (1976), the HF and LF versions differ in "ionospheric" calibration.

Planetary waves of tropospheric origin have been observed to penetrate up to heights near $110 \mathrm{~km}$ in winter (e.g. Vincent, 1990). Their upward penetration is more difficult in summer, when they can either penetrate from the winter hemisphere (e.g. Medvedev et al., 1991), or may be created in the stratosphere (e.g. Vincent, 1990). Planetary waves of tropospheric origin were shown to be transformed adequately into waves in the radio wave absorption (Laštovička et al., 1994b). The planetary wave-type oscillations in the lower ionosphere were found to be of non-solar origin (Pancheva et al., 1989; Pancheva and Laštovička, 1989), and to coincide well with oscillations in winds at corresponding altitudes (e.g. Pancheva et al., 1989). Winds from the UARS satellite confirm (Wu et al., 1994) previous findings that planetary wave activity is of a bursty nature "bursts" of activity at a given wavelength are followed by periods of relative calm and vice versa. UARS data also show that these "bursts" of activity occur only within limited latitudinal belts, not simultaneously at all latitudes.

The "ionospheric" CRISTA campaign covers the period from 1 October till 30 November 1994. The wave activity is investigated on the basis of $f_{\text {min }}$ data at constant zenith angle $\chi$, multifrequency absorption measurements during day-time at a constant solar zenith angle, and at night, sunrise and sunset, as well as phase-height measurements at $162 \mathrm{kHz}$. Thus each data series consists of daily values (e.g. one value per day which is average from morning and afternoon values at $\chi=$ constant). The studied interval belongs to the transition period between summer and winter, which is why almost all time series have well-expressed trends. The data are analyzed by first removing a parabolic trend and then, as the length of the time series is only 61 days, using the MEM method to determine the spectrum. Planetary waves in the period range of 2.5-25 days are considered.
The selected order of MEM influences to some extent spectral resolution and determination of spectral peaks. Therefore we began analysis with order $a=7$ and repeated with higher orders. Increase of order resulted in sharpening of spectral peaks and also shift of peaks. However, this process was virtually saturated at $a=9$ 11 for various peaks. Therefore all the results presented in the study were calculated with the order $a=13$, which provides "safe" results.

The MEM partly obscures the meaning of spectral resolution. However, taking into account the wellknown fact that all planetary wave type oscillations at lower ionospheric heights are quasiperiods with the period varying within a band (according to our experience with $30 \mathrm{y}$ of data, this band is for e.g. a 7.5 day period slightly more than 2 days broad), the resolution is definitely substantially better than the width of this band.

In MEM, the height of peaks is not directly connected to amplitude of wave and, therefore, to get more reliable information on the level of significance of individual peaks, we always compare MEM results with results of the correloperiodogram analysis, which provides more reliable information about statistical significance. All spectral peaks discussed in the work are significant at least at the $90 \%$ level, great majority of them at $95 \%$ level, and many at $99 \%$ level. For instance, the El Arenosillo $2830 \mathrm{kHz}$ absorption spectral peaks are significant at levels 99\% (3.8 days), 94\%(5.3 days) and $99 \%$ (16 days).

\section{$2 f_{\min }$ analysis}

The upper part of the lower ionosphere was investigated using $f_{\min }$ data from 12 ionosonde stations, which cover Europe and mid-latitudinal Asia. The list of stations with their coordinates is given in Table 1. The MEM spectrum analysis of European $f_{\text {min }}$ data shows a slight difference between the Western and Eastern parts of Europe: generally, there are fluctuations from three different bands in both regions, however the typical periods do not coincide completely. Figure $1 \mathrm{a}$, b shows the MEM spectra of West and East European $f_{\min }$ data.

Table 1. List of ionosondes with their coordinates, geographic latitudes $(\varphi)$ and geographic longitudes $(\lambda)$

\begin{tabular}{llr}
\hline Ionosonde & $\varphi\left({ }^{\circ} \mathrm{N}\right)$ & $\lambda\left({ }^{\circ} \mathrm{E}\right)$ \\
\hline Slough & 51.5 & -0.6 \\
Ebro & 40.8 & 0.5 \\
Rome & 41.8 & 12.5 \\
Kaliningrad & 54.7 & 20.6 \\
Sofia & 42.7 & 23.4 \\
Moscow & 55.5 & 37.3 \\
Irkutsk & 52.5 & 104.0 \\
Beijing & 40.0 & 116.3 \\
Okinawa & 26.3 & 127.8 \\
Yamagawa & 31.2 & 130.6 \\
Kokobunji & 35.7 & 139.5 \\
Wakkanai & 45.4 & 141.7 \\
\hline
\end{tabular}



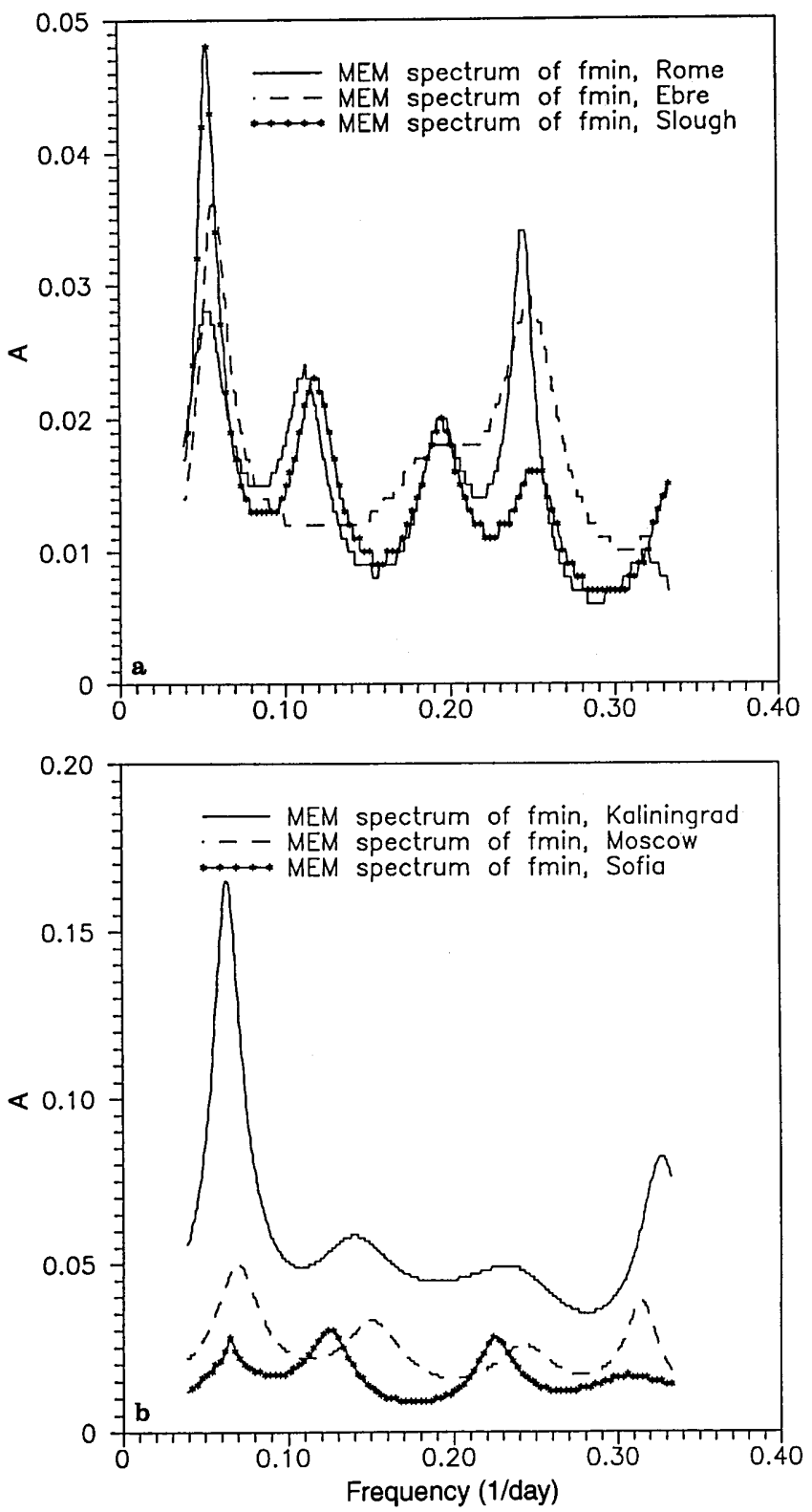

Fig. 1. MEM spectra in the period interval 3-25 days for a West European ionosonde stations: Slough (solid line with asterisks), Ebro (solid line), Rome (dashed line), and b East European stations: Kaliningrad (solid line), Sofia (solid line with asterisks), Moscow (dashed line)

The typical shortest period fluctuations for Western Europe are those with period of 4-5 days, while for Eastern Europe they cover a range of 3.2-4.3 days. The second group of fluctuations belongs to the period range of 7-8.6 days. Again the typical periods for Western Europe are longer than those for Eastern Europe (8.48.6 days and $6.8-7.8$ days, respectively). The best expressed fluctuations in all spectra are the longest ones. For Western Europe, they cover the period of 17.418.2 days, while for Eastern Europe to 14.5-16 days.

The results of autocorrelation analysis show that 4and 5-day fluctuations in Western Europe are not two different fluctuations; they are a single fluctuation with variations in the prevailing period with time. This result
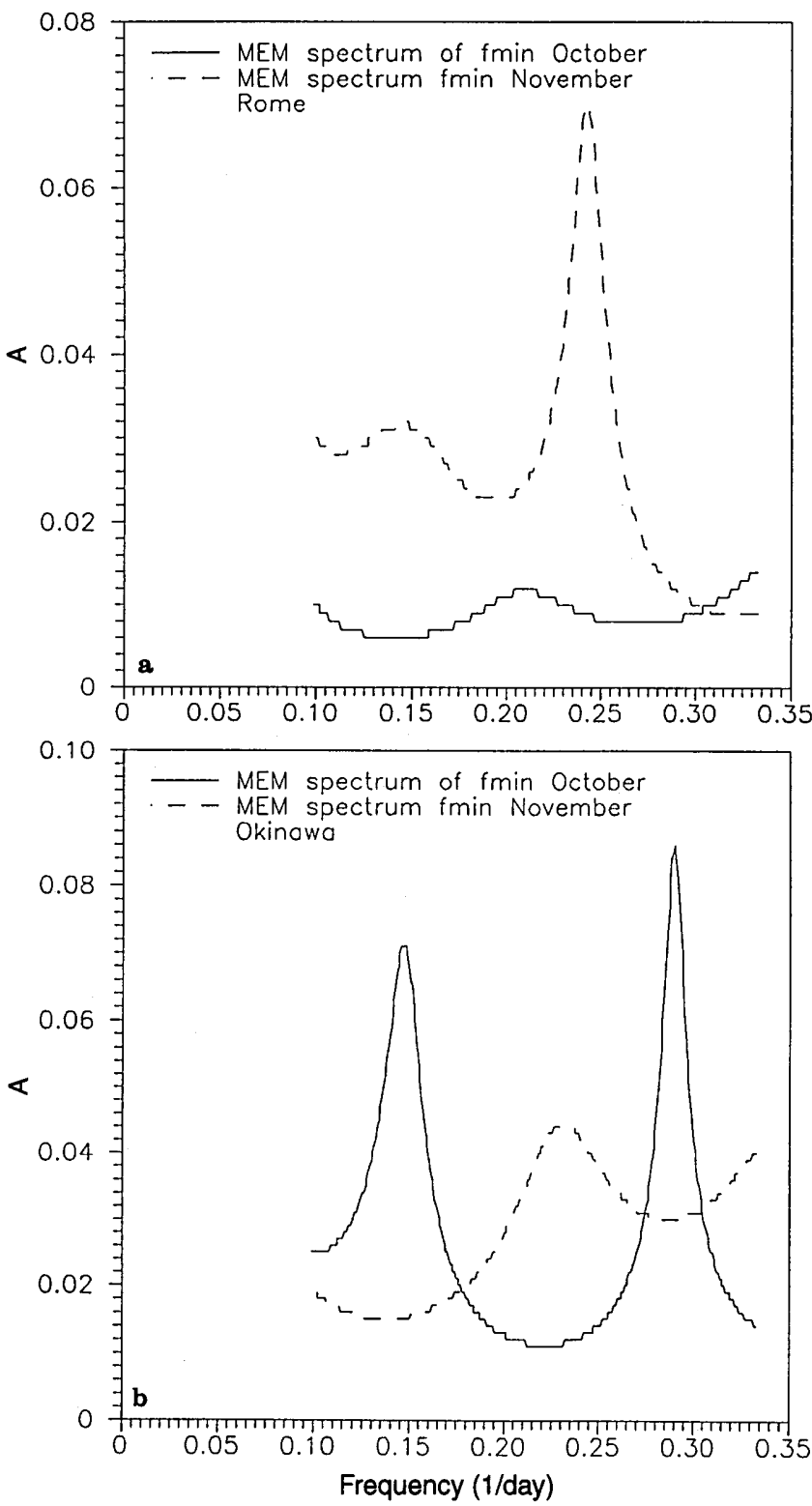

Fig. 2. MEM spectra in the period interval 3-10 days obtained separately for October (solid line) and November (dashed line) for stations: a Rome, and b Okinawa

is demonstrated in Fig. 2a, where the MEM spectra, obtained separately for October and November, are shown (station Rome). We can see: (1) an increase of the wave activity in November, and (2) a change of the typical period from about 5 days in October to about 4 days in November. The East European $f_{\min }$ data also demonstrate an increased wave activity in November and this effect is weaker only for Kaliningrad. Figure 3a shows the filtered 4-day waves for the West European $f_{\min }$ data; it is evident that these waves are amplified and well in phase in all three time series only around 5 November.

Figure $3 \mathrm{~b}$ shows the filtered 8-day waves observed in Slough and Rome and Fig. 3c the same waves in Eastern Europe. The 8-day waves in Rome are later than those waves in Slough, and also the waves in Moscow are later 

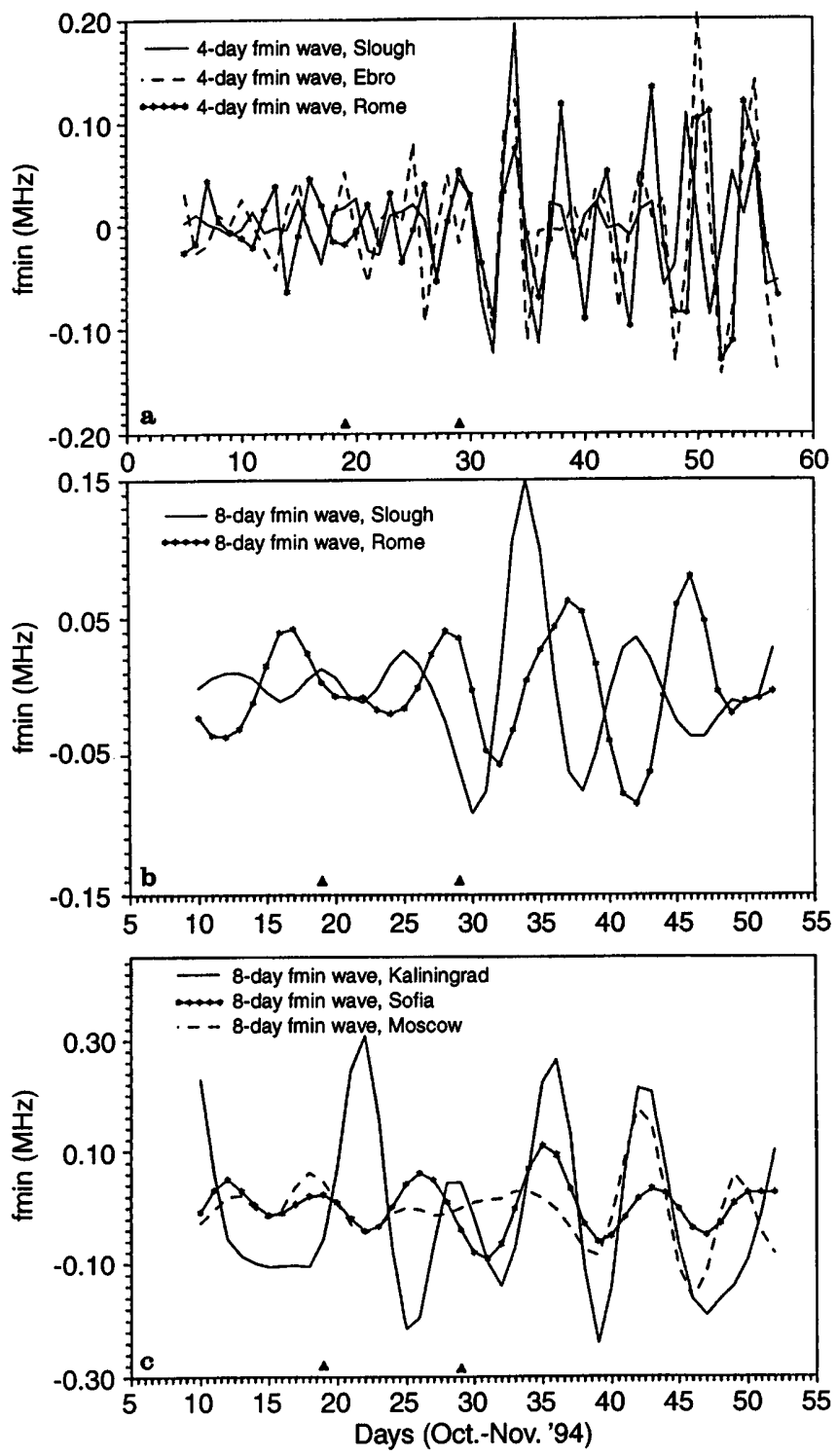

Fig. 3a-c. Filtered $f_{\min }$ data for the European stations: a $\sim 4$-day waves observed at the stations Slough (solid line), Ebro (dashed line) and Rome (solid line with asterisks); b $\sim 8$-day waves observed at Slough (solid line) and Rome (solid line with asterisks), and $\mathbf{c} \sim 8$-day waves observed at Kaliningrad (solid line), Sofia (solid line with asterisks) and Moscow (dashed line). SSCs are marked by solid triangles

those in Kaliningrad. This result indicates that 7-8 day waves propagate eastward. In Europe these waves are well expressed after 20 October, with a clearly outlined amplitude peak in the beginning of November in Western Europe.

The MEM spectrum analysis of Far East $f_{\min }$ data is shown on Fig. 4a. Figure 4b shows only the MEM spectrum for Irkutsk. This is the only $f_{\min }$ spectrum with very well-expressed 10-day fluctuations. The upper part of the Far East lower ionosphere demonstrates a similar wave behaviour as the European one. Three different period ranges are also observed: $3.2-5$ days, $6.7-8$ and 16.7-21 days. The first period band is broad, because the prevailing periods in October and November are different. Figure 2b shows MEM spectra separately for October and November (station Okinawa); the result is
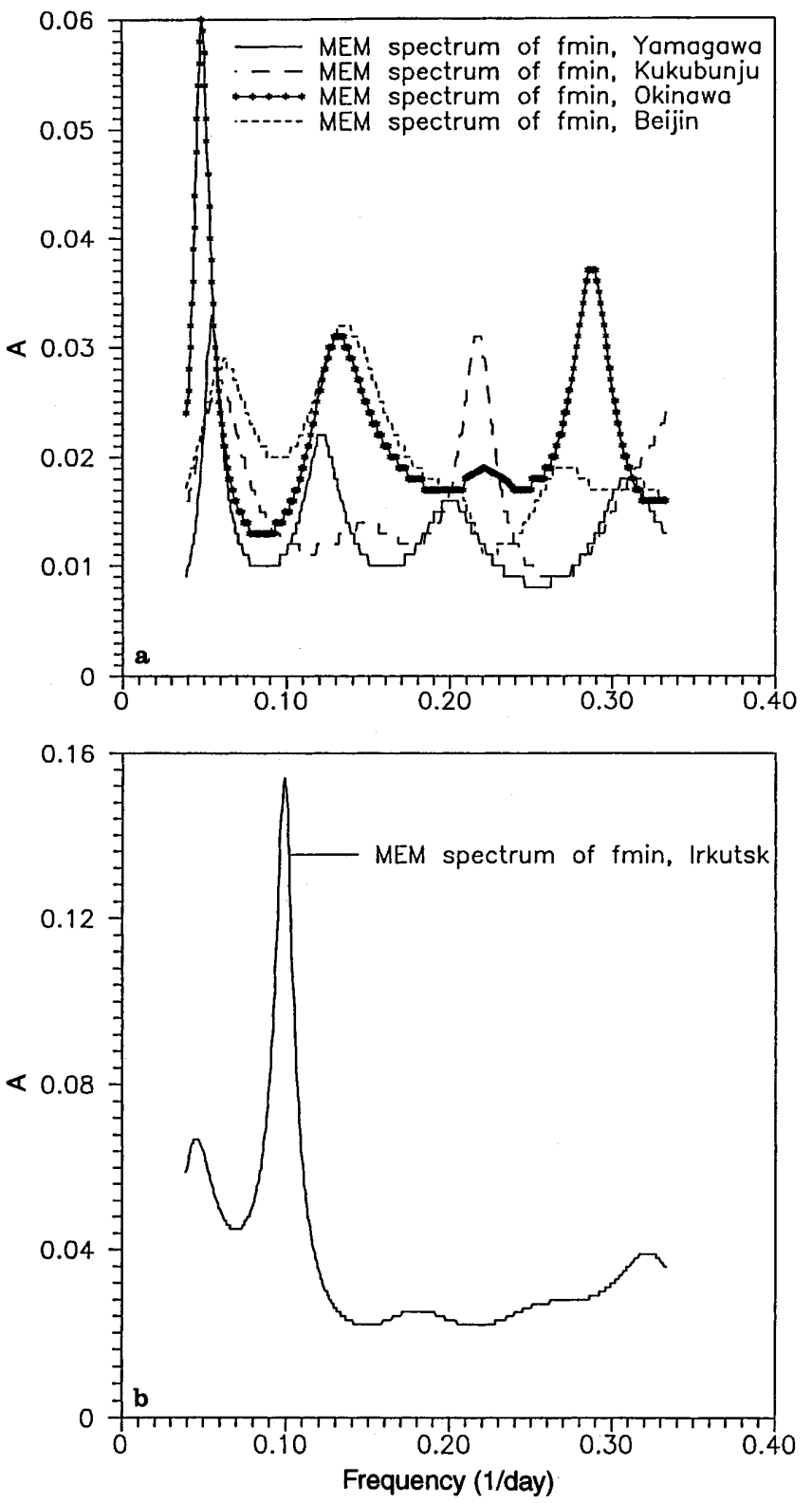

Fig. 4. MEM spectra in the period interval 3-25 days for ionosonde stations a Yamagawa (solid line), Kokubunji (longer dashed line), Okinawa (solid line with asterisks) and Beijing (dashed line), and b Irkutsk

opposite to those in Europe: (1) the wave activity is higher in October than in November, and (2) the well expressed 3.4-day fluctuation in October turns to a weaker 4.4-day one in November. Figure 5a describes the filtered 4-day fluctuations in Asian $f_{\min }$ data. There are two time intervals when the waves are amplified: they are centred around 18-20 October and 5-7 November. Figure $5 \mathrm{~b}$ displays the 7-8-day waves; they are well developed until 5 November. Generally, the waves in Beijing are ahead of these in Okinawa and Yamagawa. This fact again shows that the 7-8-day waves have eastward direction of propagation. Figure $5 \mathrm{c}$ displays the well-expressed 10-day wave observed only in Irkutsk; its amplitude reaches almost $0.5 \mathrm{MHz}$, i.e. this is really a very strong wave. 

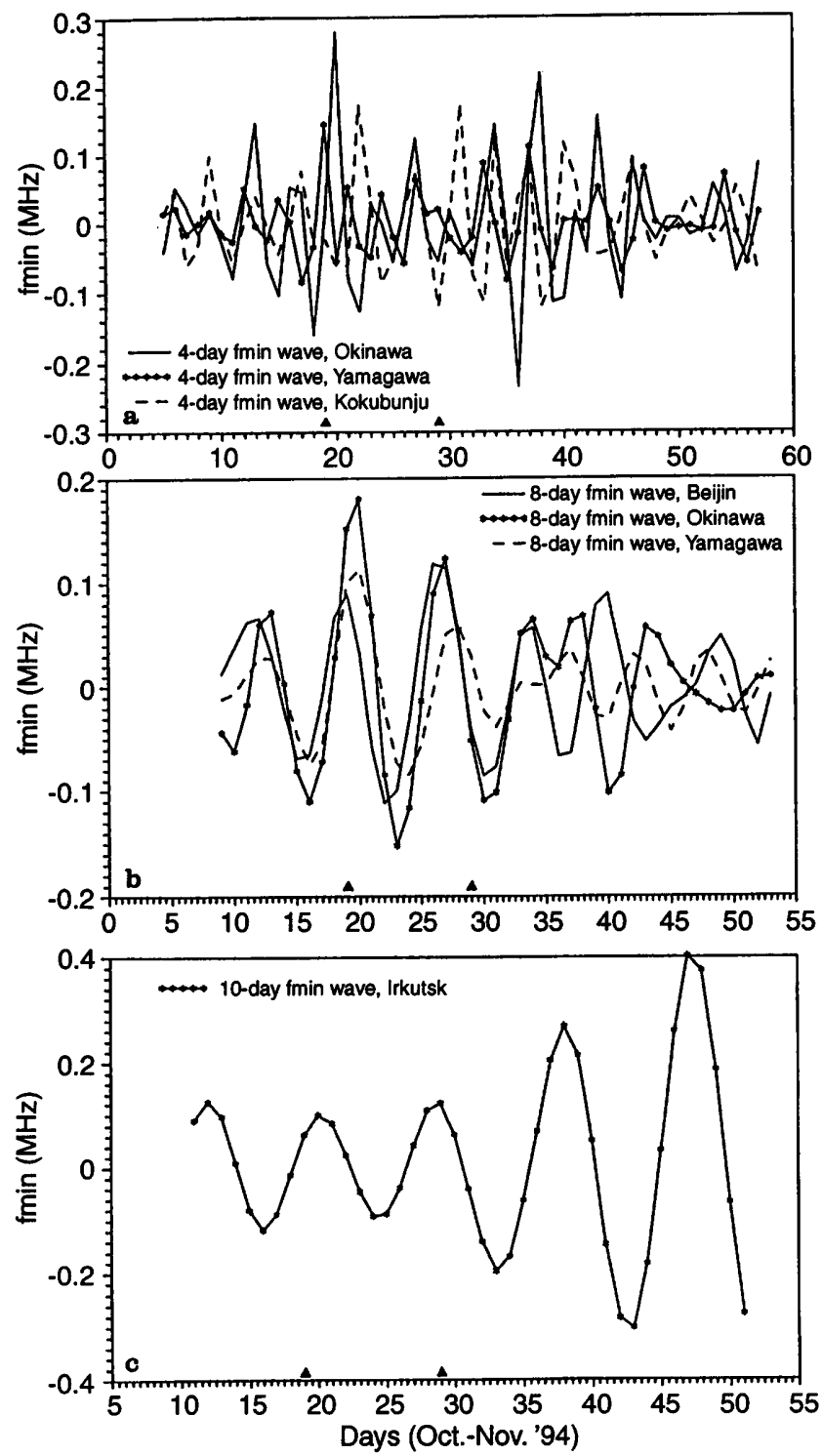

Fig. 5a-c. Filtered $f_{\min }$ data for Far East stations: a $\sim$ 4-day waves observed in Okinawa (solid line), Yamagawa (solid line with asterisks) and Kokubunji (dashed line), $\mathbf{b} \sim 8$-day waves in Beijing (solid line), Okinawa (solid line with asterisks) and Yamagawa (dashed line), and c 10-day, wave, observed only in Irkutsk. SSCs are marked by solid triangles

\section{Absorption data analysis}

The multifrequency absorption data describe the upper part of the lower ionosphere. Table 2 provides a list of A3 and IPHA radio paths used in the analysis. Data from some radio paths, such as $270 \mathrm{kHz}$, could not be used due to data gaps. The day-time HF measurements describe heights of about $90-100 \mathrm{~km}$, while the sunrise and sunset LF measurements describe heights around $85 \mathrm{~km}$.

Generally, the fluctuations pertaining to four periodic ranges are observed: 3-4, 5.6-7, 10-11 days and longer fluctuations with an average period of about 1618 days (Fig. 6). Only the LF sunset absorption data have longer average period, about 23 days. As with the
Table 2. Parameters of the A 3 absorption and IPHA circuits used - name or location of the observatory, frequency, equivalent vertical frequency, geographic latitude $(\varphi)$ and longitude $(\lambda)$ of reflection point

\begin{tabular}{lcclc}
\hline Observatory & $f(\mathrm{kHz})$ & $f_{\mathrm{eq}}(\mathrm{kHz})$ & $\varphi\left({ }^{\circ} \mathrm{N}\right)$ & $\lambda\left({ }^{\circ} \mathrm{E}\right)$ \\
\hline A3 absorption & & & & \\
EI Arenosillo & 2830 & 1200 & 38.5 & -5.3 \\
Panská Ves & 6090 & 2100 & 50.1 & 10.3 \\
Kühlungsborn & 243 & 170 & 54.9 & 11.4 \\
Kühlungsborn & 177 & 130 & 53.5 & 12.6 \\
$I P H A$ & & & 50.7 & 6.6 \\
Kühlungsborn & 162 & & 5 &
\end{tabular}

$f_{\min }$ data, in almost all absorption data the longer fluctuations are the most pronounced ones. In sunset and sunrise data, the 3-4 day fluctuations are also well developed.

Fluctuations of 10-11 days are observed only in some absorption data (analogous to $f_{\min }$ data of Irkutsk). They are the best developed fluctuation in the phase-height measurements (IPHA) at $162 \mathrm{kHz}$. The filtered 4- and 6-day waves in the day-time absorption measured at El Arenosillo and Panská Ves show very good coincidence. These fluctuations are very well developed, especially those measured in El Arenosillo. The mean amplitude of 4-day fluctuation is about $7 \mathrm{~dB}$, and about $5 \mathrm{~dB}$ for the 6-day one.

\section{Non-ionospheric data analysis}

We made an attempt to study the influence of neutral mesospheric/lower thermospheric wind, measured at Collm $\left(52^{\circ} \mathrm{N}, 15^{\circ} \mathrm{E}\right)$, as well as the geomagnetic activity, described by the $a a(N)$-index, on the wave activity in the lower ionosphere. Figure 7a shows the MEM spectra of prevailing zonal and meridional winds near $95 \mathrm{~km}$, Fig. 7b shows spectra of amplitude (ASDT) and phase (PSDT) of the semidiurnal zonal tidal wind, and Fig. 7c spectra of the solar radio flux F10.7 and geomagnetic $a a(N)$-index. The solar radio flux spectrum has a weak peak around 13.5 days and does not display peaks found in the lower ionosphere, which confirms the nonsolar origin of the observed ionospheric fluctuations. The PSDT spectrum has the only significant peak at 10 days. The remaining spectra show fluctuations, which correspond to the period ranges already found in ionospheric data: 3.3-5, 6.5-7.6 and near 17 days.

Figure $8 \mathrm{a}$ shows the time development of the $\sim 7$-day wave, observed in the geomagnetic $a a(N)$-index, Fig. $8 \mathrm{~b}$ the same wave in the night-time absorption at $243 \mathrm{kHz}$, and Fig. 8c these waves in the zonal and meridional neutral wind. The cross-correlation analysis between the waves in the $a a(N)$-index and $243 \mathrm{kHz}$ absorption shows high correlation, $R=0.86$, with the waves in the

Fig. 6. MEM spectra in the period interval 3-25 days for the A3 absorption data: day-time, night-time, sunrise and sunset, as well as for the IPHA measurements at $162 \mathrm{kHz}$ 

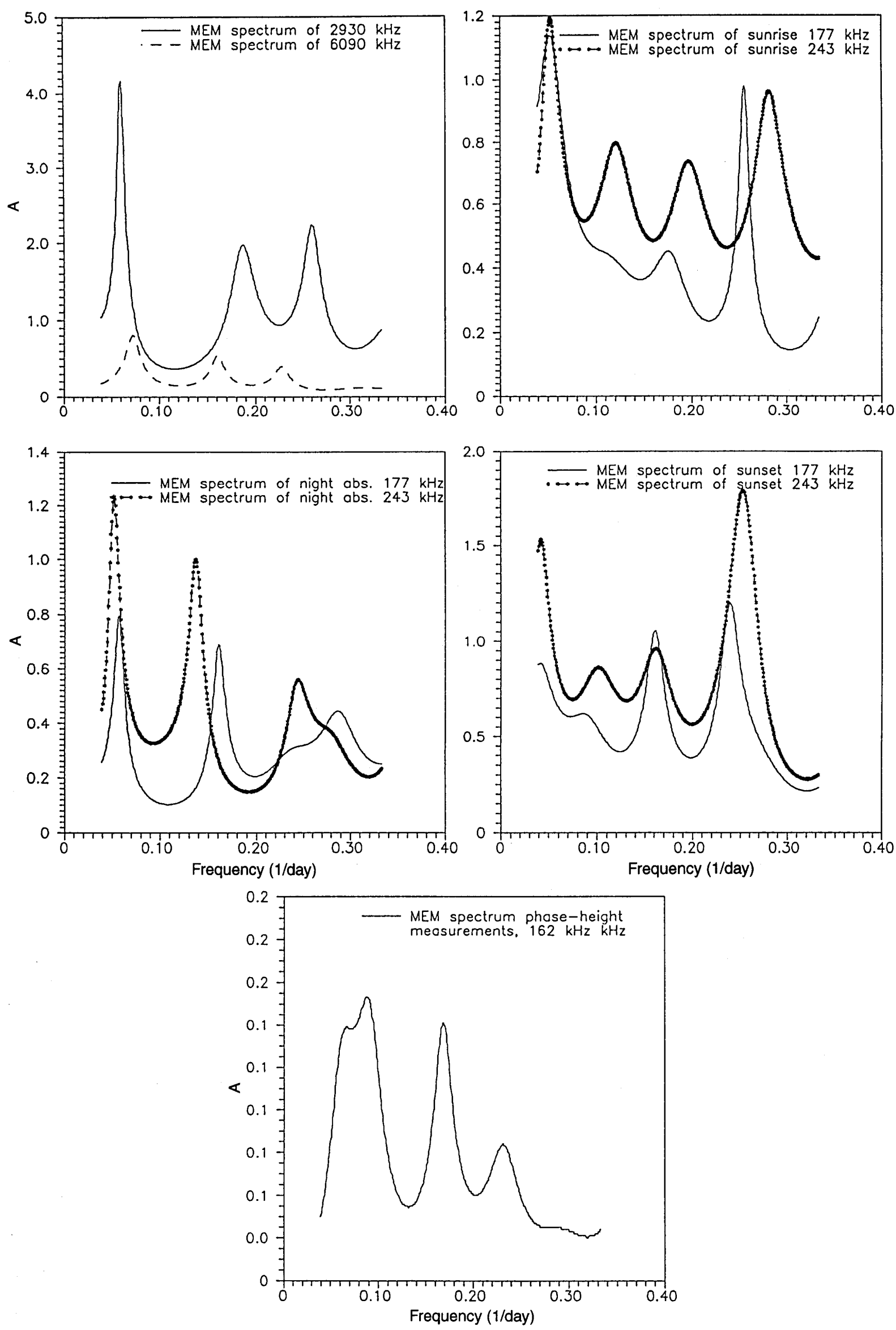
absorption lagged by about 1 day with respect to those in the $a a(N)$-index. Both sudden commencements, on 19 and 29 October, enhance the fluctuations. However, it should be mentioned that the $243 \mathrm{kHz}$ path as the northernmost one is considerably more sensitive to geomagnetic activity than other ionospheric data used. The $243 \mathrm{kHz}$ absorption has even been used for catalogue of the energetic particle-induced contribution to radio wave absorption at mid-latitudes (Lauter, 1979).

Very well developed 7-day waves are observed also in the prevailing wind (Fig. 8c). Their relation to similar waves in geomagnetic activity might be only by chance. Even if this were not the case, it is ambiguous. On the one hand, winds near $95 \mathrm{~km}$ in central Europe are known to respond to geomagnetic storms (Singer et al., 1994). On the other hand, planetary waves were found to affect geomagnetic field via modulation of ionospheric dynamo winds (Kohsiek et al., 1995). Thus even in case of a real coincidence, the cause-and-effect relation is not clear.

Dominant periods in all analyzed parameters are summarized in Table 3.

\section{Wave number analysis}

The zonal wave number $K$ can be obtained on the basis of a phase analysis for a two-station pair with longitudes $\lambda_{1}$ and $\lambda_{2}\left(\lambda_{2}>\lambda_{1}\right)$, where the waves have one and the same period $T$. If $t_{1}$ and $t_{2}$ are the respective phases, or the times when a wave crest with period $T$ passes by the longitudes $\lambda_{1}$ and $\lambda_{2}$, then:

$K=\left(360^{\circ} / T\right) \times\left[\left(t_{1}-t_{2}\right)\left(\lambda_{2}-\lambda_{1}\right)\right]$

$K>0$ corresponds to a westward propagation.

\subsection{Four-day fluctuations}

Unfortunately, the result of the phase analysis is doubtful. On the basis of $f_{\min }$ for European stations excluding Sofia, the direction of propagation is found to be westward, with very probable wave number $K=4$. However, this result was confirmed neither by other $f_{\min }$ stations in Asia, nor by the absorption measurements.

\subsection{Seven-eight-day fluctuations}

For the interval 20 October-30 November 1994 several $f_{\min }$ stations have well developed exactly 8 -day waves. The phase analysis gives the result:

Fig. 7. MEM spectra in the period interval 3-25 days for a zonal (solid line) and meridional (dashed line) neutral wind measured at Collm, b amplitudes (solid line) and phases (dashed line) of the semidiurnal tide in zonal wind, and c solar radio flux F10.7 (solid line) and geomagnetic $a a(N)$-index (dashed line)
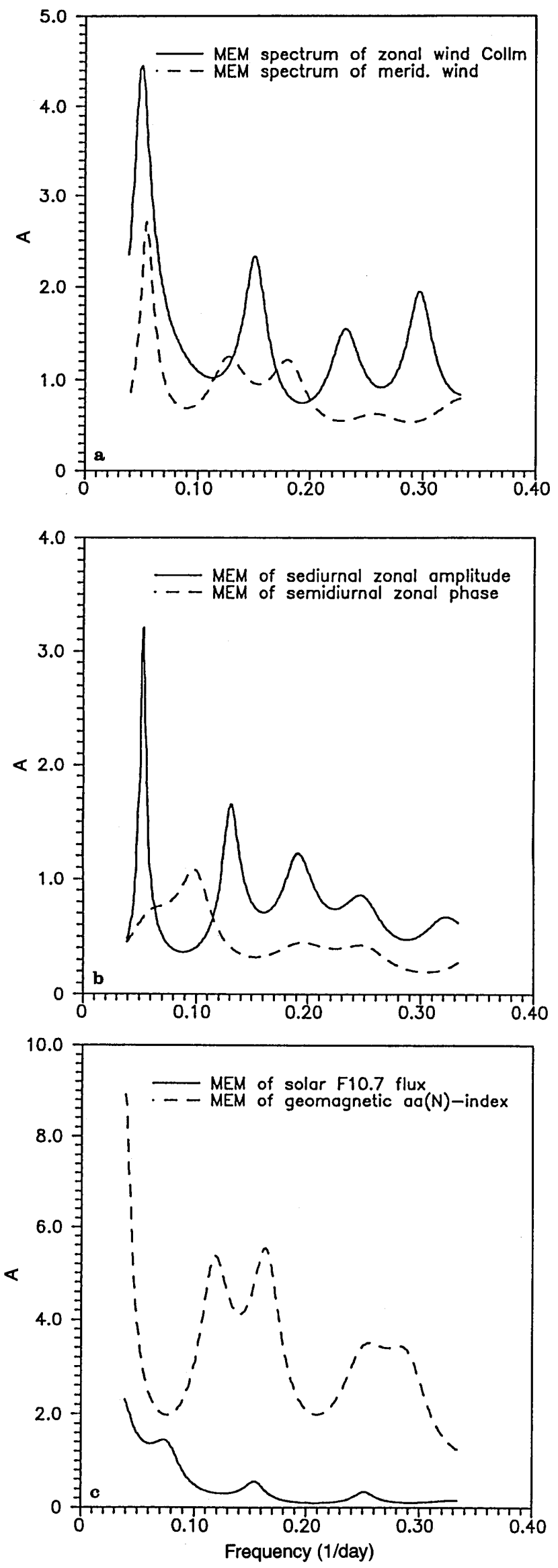

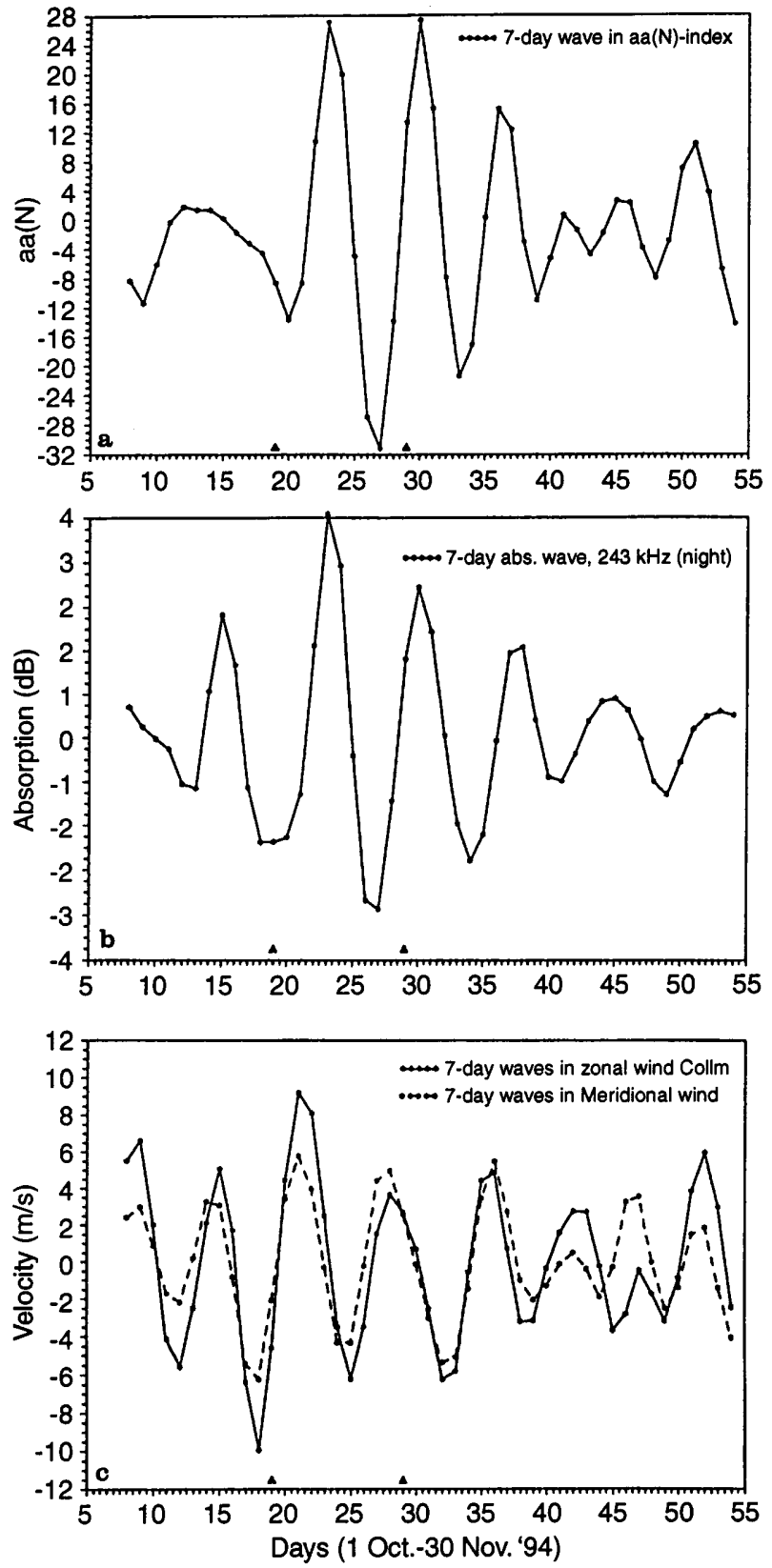

Fig. 8. About 7-day waves observed in a the geomagentic $a a(N)$ index; b the night-time absorption measured at $243 \mathrm{kHz}$, and $\mathbf{c}$ the zonal (solid line) and meridional (dashed line) neutral wind. SSCs are marked by solid triangles

\begin{tabular}{lll} 
Station & $t_{i}$ & $\lambda_{i}$ \\
\hline Slough & 0.7 & $0^{\circ}$ \\
Kaliningrad & 2.1 & $20^{\circ}$ \\
Moscow & 3.2 & $38^{\circ}$ \\
Beijing & 7.9 & $116^{\circ}$ \\
Wakkanai & 2.0 & $141^{\circ}$
\end{tabular}

On the basis of a two-station pair Beijing-Slough we obtain $K=-2.8$, and for the pair Moscow-Slough $K=-2.96$. Consequently, $K=-3$ and 8-day waves propagate eastward. The absorption data show predominantly 7.5-day waves:

\begin{tabular}{lll} 
Radio circuit & $t_{i}$ & $\lambda_{i}$ \\
\hline $2830 \mathrm{kHz}$ (day) & 0.28 & $-5.3^{\circ}$ \\
$6090 \mathrm{kHz}$ (day) & 1.28 & $-10.3^{\circ}$ \\
$177 \mathrm{kHz}$ (night) & 1.45 & $-12.6^{\circ}$
\end{tabular}

On the basis of absorption results we obtain $K=3.1$, or on the average, 7-8-day waves have wave number 3 and eastward direction of propagation.

\subsection{6-17-day fluctuations}

$f_{\min }$ data show predominantly 17 -day waves:

\begin{tabular}{lll} 
Station & $t_{i}$ & $\lambda_{i}$ \\
\hline Ebro & 4.5 & $0.5^{\circ}$ \\
Beijing & 10.8 & $116^{\circ}$
\end{tabular}

The wave number obtained on the basis of the above phase results is $K=-1.16$. The absorption data show predominantly 16-day fluctuations. The phase analysis shows:

\begin{tabular}{lll} 
Radio circuit & $t_{i}$ & $\lambda_{i}$ \\
\hline $2830 \mathrm{kHz}$ (day) & 4.34 & $-5.3^{\circ}$ \\
$6090 \mathrm{kHz}$ (day) & 5.16 & $10.3^{\circ}$
\end{tabular}

The wavenumber is: $K=-1.18$. Consequently, on the basis of both $f_{\min }$ and absorption and absorption data the wavenumber for the 16-17-day wave is $K=-1$ and direction of propagation is again eastward.

The possibility that there might be a phase variation with latitude must not be excluded a priori. Such a variation would modify the determination of zonal wave numbers. However, the results from various pairs of stations are very close each other. For 16-17 day waves, Ebro and Beijing are located at almost identical latitudes (Table $1-\varphi=0.8^{\circ}$ ), while their longitudes are very different $\left(\lambda=115.8^{\circ}\right)$. For $7-8$ day waves, the pairs of stations Slough-Moscow and Slough-Beijing have their eastern partners Moscow and Beijing located by $4^{\circ}$ more to the north and $11.5^{\circ}$ more to the south, respectively, but the difference in wave numbers is very small, both are considered to be approximately $n=-3$. Thus an influence of phase variation with latitude on determination of wave numbers may be neglected.

\section{Long-term comparison}

The longest available planetary wave activity data series, as inferred from the $6090 \mathrm{kHz}$ absorption measurements since 1971 (e.g. Laštovička et al., 1994c), is used to estimate the extent to which the planetary wave activity in the lower ionosphere corresponds to the expected one, i.e. to the expected long-term "climatological" magnitude of planetary wave activity. There is no solar cycle influence on the $6090 \mathrm{kHz}$-inferred planetary wave activity (Laštovička, 1993). However, these data show a positive trend from the early 1970s to early 1983, followed by period of no trend (Laštovička et al., 1994c). Only the latter "trend-free" part of data series is 
Table 3. Summary of dominant periods in the periodical bands: $3-5,6-8,10-11$ and $15-$ 23 days, observed in $f_{\min }$ data, A3 absorption and IPHA measurements, winds near $95 \mathrm{~km}$ (ASDT, PSDT - amplitude and phase of semidiurnal tide), solar $\left(\mathrm{F}_{10.7}\right)$ and geomagnetic $(a a)$ activity indices

\begin{tabular}{|c|c|c|c|c|}
\hline Station & $3-5$ & $6-8$ & $10-11$ & $15-23$ \\
\hline Slough & $3.9-5$ & 8.3 & \multirow{16}{*}{10.1} & 18.2 \\
\hline Ebro & 4 & & & 17.4 \\
\hline Rome & 4.1 & 8.4 & & 18.0 \\
\hline Kaliningrad & $3.1-4.3$ & 7.1 & & 15.6 \\
\hline Sofia & 4.3 & 7.8 & & 15.5 \\
\hline Moscow & $3.2-4.1$ & 6.8 & & 14.5 \\
\hline Irkutsk & 3.2 & & & 21.0 \\
\hline Beijing & 3.8 & 7.3 & & 16.7 \\
\hline Yamagawa & $3.2-5.0$ & 8.2 & & 17.8 \\
\hline Kokobunji & 4.6 & 8.0 & & 16.8 \\
\hline Wakkanai & 4.2 & 6.7 & & 20.7 \\
\hline Okinawa & $3.4-4.4$ & 7.6 & & 20.1 \\
\hline $2830 \mathrm{kHz}(\cos \chi=0.2)$ & 3.9 & 6.0 & & 16.7 \\
\hline $6090 \mathrm{kHz}\left(\chi=75^{\circ}\right)$ & 4.4 & 6.2 & & 14.7 \\
\hline 177 kHz (night) & 3.4 & 6.2 & & 17.4 \\
\hline 243 kHz (night) & 4.0 & 7.2 & & 18.9 \\
\hline 177 kHz (sunset) & 4.1 & 6.2 & 11.3 & 23.0 \\
\hline 243 kHz (sunset) & 4.0 & 6.2 & 10.0 & 23.3 \\
\hline 177 kHz (sunrise) & 4.0 & 5.9 & \multirow{6}{*}{9.8} & 18.9 \\
\hline 243 kHz (sunrise) & 3.7 & 5.8 & & 18.9 \\
\hline IPHA & 4.3 & 6.0 & & 14.8 \\
\hline Zonal wind (Collm) & $3.3-4.4$ & 6.5 & & 17.0 \\
\hline Merid wind (Collm) & 5.1 & 7.6 & & 17.0 \\
\hline ASDT & 5.1 & 7.4 & & 17.0 \\
\hline PSDT & & & \multirow[t]{3}{*}{10.0} & \\
\hline$F_{10.7}$ solar flux & & & & 13.5 \\
\hline$a a(A)$-index & $3.4-4.0$ & $6.5-7.5$ & & \\
\hline
\end{tabular}

used for comparison, October-November 1983-1994 (data gap in 1995; measurements terminated in September 1996). The planetary wave activity data are available as the maximum amplitudes of two-month average spectra within period bands of 4-6 and 9-11 days, which represent $\sim 5$ - and $\sim 10$-day oscillations.

The 5-day oscillations have amplitudes within the range of $0.57-1.82 \mathrm{~dB}$ with median value of $0.97 \mathrm{~dB}$, mean $1.08 \mathrm{~dB}$ and $\sigma=0.47 \mathrm{~dB}$, while the actual CRISTA 1994 value is $0.75 \mathrm{~dB}$. The 10-day oscillations have amplitude within the range of $0.54-1.51 \mathrm{~dB}$ with median value of $0.97 \mathrm{~dB}$, mean 1.01 and $\sigma=0.28 \mathrm{~dB}$, while the 1994 value is $0.86 \mathrm{~dB}$. Thus the CRISTA interval planetary wave activity is somewhat less than the average but well within the interval of observed values. Hence the planetary wave activity in the CRISTA interval may be considered undisturbed and not much different from the climatological value. It should be noted that the average October-November planetary wave activities near 5- and 10-days during the twelve analysed years vary independently of each other, the correlation between them is $R=0$.

\section{Conclusion}

The planetary wave analysis of $f_{\text {min }}$, multifrequency A3 absorption and IPHA data, describing the lower ionosphere (heights of about $80-100 \mathrm{~km}$ ) shows the existence of planetary wave-type fluctuations belonging to three period bands: $3-5,6-8$ and 15-23 days. Only a few data series have fluctuations with a period of about 10-11 days, which is why these fluctuations are not studied in detail here. The best expressed fluctuations in all data sets are the longest ones.

The ionospheric data do not provide a consistent pattern for the $\sim 4$-day waves, in spite of the fact that they can be observed in all data sets. The time intervals of amplification of these waves are different for different regions. The attempt to find their wave number was of doubtful value, from European $f_{\min }$ data we obtained a westward propagation with probable wave number $K=4$, whereas Asian $f_{\min }$ and absorptions do not provide any consistent wave number.

The spatial pattern for the longer waves of periods about 7-8 and 16-18 days in the lower ionosphere is more consistent. The wave number analysis displays that both planetary waves have an eastward direction of propagation. The wave number of the 7-8-day waves is $K=3$, while that of the 16-18-day it is $K=1$.

The question why planetary waves propagate eastward (they should propagate westward at mid-latitudes according to standard theory) remains open. First it is necessary to collect autumnal data from stations used in this study for at least 10-15 years (including tests of their quality and reliability) to check if the eastward propagation in the mid-latitudinal upper middle atmosphere is a regular autumnal phenomenon or rather an anomaly. This is scope of another paper. It should be mentioned, however, that as shown by this work and by Laštovička et al. (1997), October-November 1994 does not seem to be anomalous from several other points of view.

The comparison of amplitudes of 5- and 10-day fluctuations with results of previous $11 \mathrm{y}$ for the $6090 \mathrm{kHz}$ data shows that the magnitude of planetary 
wave activity corresponds to undisturbed conditions, not much different from climatological values.

In conclusion we may say that the pattern of planetary wave activity in the middle latitudes of the Northern Hemisphere during the CRISTA campaign (October-November 1994) does not differ much and/or is fairly consistent with the expected undisturbed normal/climatological state of the atmosphere at altitudes of $80-100 \mathrm{~km}$. The only unexpected result is the eastward propagation of dominant planetary waves. It is the task of future investigations to find if the eastward propagation is or is not typical for the OctoberNovember period, because generally the westward propagation prevails.

Acknowledgements. Topical Editor F. Vial thanks W. Ward and another referee for their help in evaluating this paper.

\section{References}

Hauchecorne, A., N. Gonzales, C. Souprayen, A. H. Manson, C. E. Meek, W. Singer, A. H. Fahrutdinova, U. -P. Hoppe, J. Boška, J. Laštovička, J. Scheer, E. R. Reisin, and H. Graef, Gravitywave activity and its relation with prevailing winds during DYANA, J. Atmos. Terr. Phys., 56, 1765-1778, 1994.

Kohsiek, A., K. H. Glassmeier, and T. Hirooka, Periods of planetary waves in geomagnetic variations, Ann. Geophysicae, 13, 168-173, 1995.

Laštovička J., Planetary wave activity in the upper middle atmosphere inferred from radio wave absorption and the quasi-biennial oscillation, Ann. Geophysicae, 11, 820-827, 1993.

Laštovička J., Long-term trends in the upper middle atmosphere as detected by ionospheric measurements, Adv. Space Res., 20 (11), 2065-2073, 1997.

Laštovička, J., and $\mathbf{J}$. Madčra, A3 ionospheric absorption measurements on $1539 \mathrm{kHz}$ at Panská Ves, Studia Geophys Geod., 26, 381-388, 1982.

Laštovička J., L. F. Alberca, E. A. Benediktov, J. Boška, J. Bremer, G. Entzian, V. Fišer, J.-C. Jodogne, A. K. Knyazev, F. Märcz, B. A. de la Morena, PI. Mukhtarov, T. Ogawa, D. Pancheva, H. Ranta, Z. Ts. Rapoport and Xiong Nianlu, Lower ionosphere at middle latitudes: Its morphology and response to meteorological and solar-terrestrial activity during the DYANA campaign 1990, J. Atmos. Terr. Phys., 56, 1947-1962, 1994a.

Laštovička, J., A. Ebel, and A. Ondrášková, On the transformation of the planetary waves of tropospheric origin into waves in radio wave absorption in the lower ionosphere. Studia Geophys. Geod., 38, 71-81, 1994b.

Laštovička, J., V. Fišer, and D. Pancheva, Long-term trends in planetary wave activity ( $2-15$ days) at $80-100 \mathrm{~km}$ inferred from radio wave absorption, J. Atmos. Terr. Phys., 56, 893-899, 1994c.
Laštovička, J., D. Burešová, J. Boška, J. Bremer, and F. Märcz, Do CRISTA experiment/campaign data represent a typical situation or not?, Studia Geophys Geod., 41, 171-180, 1997.

Lauter, E. A., A catalogue of particle-induced ionospheric absorption at mid-latitudes, 1948-1978, Z. Meteorol., 29, 279292, 1979.

Lauter, E. A., J. Bremer, G. Entzian, and K. Sprenger, Method A3 (B): oblique incidence field strength observations on frequencies in and below the MF broadcasting band, in: Manual of ionospheric Absorption Measurements, Ed. K. Rawer, WDC-A Rep. UAG-57, 147-163, Boulder, 1976.

Lauter, E. A., J. Taubenheim, G. von Cossart, Monitoring middle atmosphere processes by means of ground-based low-frequency radio wave sounding of the D-region, J. Atmos. Terr. Phys., 46, 775-780, 1984.

Medvedev, S. A., A. I. Pogoreltsev, and S. A. Sukhanova, Modelling of the global structure and penetration across equator of planetary waves, Fiz. Atmos. Okeana, 27, 813-824, 1991 (in Russian).

Offermann, D., CRISTA: a space shuttle experiment for middle atmosphere small scale structures, In: CRISTA/MAHRSI Campaign Handbook, Eds. M. Bittner and D. Offermann, 2234, University of Wuppertal, Wuppertal, Germany, 1994.

Pancheva, D., and J. Boška, Solar or meteorological control of lower ionospheric fluctuations (2-15 and 27 days) in middle latitudes, Handbook for MAP, 29, 210-214, 1989.

Pacheva, D., and J. Laštovička, Solar or meteorological control of lower ionospheric fluctuations (2-15 and 27 days) in middle latitudes, Handbook for MAP, 29, 119-128, 1989.

Pancheva, D., E. Apostolov, J. Laštovička, and J. Boška, Longperiod fluctuations of meteorological origin observed in the lower ionosphere, J. Atmos. Terr. Phys., 51, 381-388, 1989.

Pancheva, D., J. Laštovička, and B.A. de la Morena, Quasi-periodic fluctuations in ionospheric absorption in relation to planetary activity in the stratosphere, J. Atmos. Terr. Phys, 53, 1151-1156, 1991.

Pancheva, D., A. Anufriev, and J. Laštovička, Planetary wave activity in the lower ionosphere during the DYANA campaign, J. Atmos. Terr. Phys., 56, 1963-1968, 1994.

Schwentek, H., Wave-like structures in the variation of ionospheric absorption, J. Atmos. Terr. Phys., 36, 1173-1182, 1974.

Singer, W., P. Hoffmann, A. H. Manson, C. E. Meek, R. Schminder, D. Kurschner, G. A. Kokin, A. Knyazev, Y. I. Portnyagin, N. A. Makarov, A. N. Fahrutdinova, V. V. Sidorov. G. Cevolani, H. G. Muller, E. S. Kazimirovsky, V. A. Gaidukov, R. R. Clark, R. P. Chebotarev, and Y. Karadjaev, Geomagnetic influences upon tides - winds from MLT radars, J. Atmos. Terr. Phys., 56, 13011311, 1994.

Vincent, R. A., Planetary and gravity waves in the mesosphere and lower thermosphere, Adv. Space Res., 10, (12) (CIRA 1986), 93$101,1990$.

Wu, D. L., P. B. Hays, and W. R. Skinner, Observations of the 5day wave in the mesosphere and lower thermosphere, Geophys. Res. Lett., 21, 2733-2736, 1994. 